\title{
NILAI-NILAI SUFISTIK TOKOH WAYANG SEMAR DAN IMPLIKASINYA TERHADAP PENDIDIKAN ISLAM
}

\section{THE SUFISTIC VALUES OF THE WAYANG SEMAR FIGURE AND THE IMPLICATIONS ON ISLAMIC EDUCATION}

\author{
Rudy Al-Hana \\ Universitas Islam Negeri Sunan Ampel Surabaya, Indonesia \\ Email: rudy.alhana@uinsby.ac.id \\ M. Yusuf \\ Universitas Islam Negeri Sunan Ampel Surabaya, Indonesia \\ Email: yusuf.much21@gmail.com
}

\begin{abstract}
Abstrak
Artikel ini bertujuan untuk menjelaskan nilai-nilai sufistik yang terkandung dalam tokoh wayang Semar serta implikasinya terhadap pendidikan Islam. Semar merupakan simbol pamong dan pengayom, untuk itu perilakunya sama dengan perilaku sang mursyid. Nilai-nilai sufistik yang diajarkan oleh Semar ialah syariat atau sembah raga; tarekat atau sembah kalbu; hakekat atau sembah jiwa; makrifat atau sembah rasa; dan mahabbah atau cinta suci -asmarasanta. Hal ini mengindikasikan bahwa yang diajarkan Semar sebagaimana karakteristik tasawuf amali. Kemudian Semar juga mengajarkan rasa eling, sahid/asetik/pertapa, sabar, dan ridha atau ikhlas; hal ini juga sesuai dengan karakteristik tasawuf akhlaqi. Sedangkan karakteristik falsafi sebagaimana digambarkan oleh Semar dengan ajarannya "manunggaling kawula lawan Gusti." Nilai-nilai sufistik tokoh wayang Semar ini mengandung implikasi secara filosofis, pedagogis teoritis, dan praksis.
\end{abstract}

Kata Kunci: tasawuf, wayang, Semar, pendidikan Islam

\section{Abstract}

This article aims to explain the Sufistic values contained in the wayang Semar character and their implications for Islamic education. Semar is a symbol of guardian and protector, for that his behavior is the same as that of the mursyid. The Sufistic values taught by Semar are shari'a or worship; tarekat or worship of the heart; essence or worship of the soul; makrifat or worship of taste; and mahabbah or holy love -asmarasanta. This indicates that what Semar is teaching is as characteristic of amali Sufism. Then Semar also teaches a sense of eling, sahid/ascetic, patient, and happy or sincere; this is also in accordance with the characteristics of akhlaqi Sufism. While the characteristics of philosophy as described by Semar with his teaching "manunggaling kawula lawan Gusti." The Sufistic values of the wayang Semar character contain philosophical, theoretical pedagogical, and praxis implications.

Keywords: sufism, puppet, Semar, Islamic education 


\section{A. Pendahuluan}

Dewasa ini globalisasi sudah merambah di urat nadi kehidupan manusia, pengaruhnya sangat luar biasa kompleks dan signifikan. Untuk itu, manusia harus bisa membentengi dirinya dari pengaruh tersebut dengan memahami potensi yang ada pada diri masing-masing, baik secara lahiriyah atau spiritual. Kesenjangan antara dunia dengan akhirat biasa terjadi. Dalam situasi demikian, tasawuf jelas sangat dibutuhkan. ${ }^{1}$ Tidak hanya itu, degradasi moral juga juga telah dialami oleh manusia modern. Harun Nasution mengingatkan, bahwa keresahan bisa terjadi jika konsep Barat yang didasarkan pada filsafat sekular dibawa dalam pendidikan modern masyarakat agamis Indonesia. Lanjutnya, sekularisme sudah nyata menjadi musuh terbesar dari agama. ${ }^{2}$

Aspek rasional -aql- juga sangat diagungkan oleh masyarakat modern tanpa mengedepankan aspek hati - qalb, padahal, keduanya tidak ada dikotomi dalam agama. Jika demikian itu dibiarkan, maka akan semakin berakibat fatal. Akal/rasio manusia jelas terbatas, ketika terjadi masalah dan tak ada jalan untuk menyelesaikan masalahmasalah tersebut, yang terjadi ialah stress yang mereka keluhkan, depresi, bahkan sampai bunuh diri. Untuk itulah, hati mengambil posisi, ia menjadi sekoci ketika kapal besar mulai karam. Hati yang akan membisikkan sebuah ketenangan dan kesabaran. Tasawuf/nilai-nilai sufistik yang akan memberikan penawar juga menjadi penyeimbang antara akal dengan hati ketika bergejolak. Nilai-nilai sufistik akan mengajarkan kehidupan yang benar, rajin olah ibadah, berakhlak mulia, serta mendapatkan ketentraman hidup di dunia dengan mendekatkan diri pada Sang Pencipta. ${ }^{3}$ Jika seluruh warga masyarakat melaksanakan nilai-nilai sufistik dengan benar, kemungkinan besar bisa membawa masyarakat ke arah yang lebih baik, moral dan spiritualnya.

Salah satu kekayaan yang dimiliki oleh bangsa Indonesia ialah budaya yang dimiliki oleh rakyatnya. Tiap daerah memiliki budaya masing-masing. Itu semua merupakan anugerah yang diberikan oleh Tuhan untuk selalu dijaga dan dilestarikan. Perlu adanya upaya revitalisasi dan rekonstruksi nilai-nilai moral yang sesuai dengan

\footnotetext{
${ }^{1}$ Achmad Husen, et.al., "Pendidikan Karakter Berbasis Spiritualisme Islam (Tasawuf)," Jurnal Studi Al-Qur'an; Membangun Tradisi Berfikir Qur'ani, Vol. 10, No. 1 (2014): 1-19.

${ }^{2}$ Harun Nasution, Filsafat Dan Mistisisme Dalam Islam (Jakarta: Bulan Bintang, 1973).

${ }^{3}$ Benny Prasetiya, Bahar Agus Setiawan, dan Sofyan Rofi, "Implementasi Tasawuf dalam Pendidikan Agama Islam: Independensi, Dialog Dan Integrasi," POTENSIA: Jurnal Kependidikan Islam, Vol. 5, No. 1 (2019): 64, https://doi.org/10.24014/potensia.v5i1.6553.
} 
budaya masyarakat Indonesia. Salah satu budaya yang sarat akan ajara moral dan nilainilai tasawuf ialah tokoh wayang Semar.

Semar merupakan anggota punakawan dalam kreasi pewayangan Indonesia. keberadaan Semar sangat berpengaruh terhadap suasana kebatinan masyarakat Indonesia, khususnya masyarakat Jawa. Kemunculannya sering membuat pemadam huru-hara/disharmoni kehidupan yang sering disebut dengan gara-gara ${ }^{4}$. Kemunculannya dalam pewayangan memuat banyak nilai-nilai sufistik/tasawuf dalam kehidupan, termasuk di dalamnya moral dalam menjadi manusia yang sempurna. Upaya penggalian nilai-nilai sufistik ini nampak penting ketika terdapat kesadaran bahwa moralitas sebagai penanda karakter dan jati diri diperlukan dalam kehidupan sehari-hari.

Praktik kesufian akan menjadi tren dan primadona karena manusia merasakan kepejenuhan duniawi, terutama masyarakat urban, yang mana mereka menyebut sebagai urbansufism. Praktik semacam ini ternyata mampu memberikan dampak bagi sosial bahkan dalam dunia pendidikan Islam juga memiliki kolerasi yang erat. Dari permasalahan itulah bahwa pentingnya menjelaskan bagaimana nilai-nilai sufistik yang terkandung dalam tokoh wayang Semar serta implikasinya dengan pendidikan Islam.

Sebelumnya, ada beberapa artikel yang membahas tentang tokoh wayang Semar, yakni penelitian yang dilakukan oleh Afina Izzati dengan judul "Nilai-Nilai Konstruk Harmoni: Perspektif Tokoh Wayang Semar." Dalam artikel ini peneliti sebelumnya mencoba menemukan formulasi nilai filosofis yang ada pada diri Semar untuk membangun harmonisasi antar umat beragama. ${ }^{5}$ Kedua, artikel yang ditulis oleh Oke Setiawan, I Made Kartika Dhiputra, dan Ni Nyoman Sudiani dengan judul "Nilai-Nilai Filosofis Dalam Karakter Tokoh Wayang Semar Perspektif Pendidikan Masyarakat Hindu Jawa di Pringsewu Lampung." Kedua artikel di atas sama-sama membahas tentang nilai filosofis yang ada pada diri Semar, namun konteks dari artikel yang kedua lebih ke arah pengembangan pendidikan masyarakat agama Hindu. ${ }^{6}$ Ketiga, artikel yang ditulis oleh Nanik Herawati, D. B. Putut Setiadi, dan Erry Pranawa dengan judul "Figure of Semar in the Javanese Puppet Story as a Symbol of Character Building in the

\footnotetext{
${ }^{4}$ Sri Mulyono, Wayang dan Filsafat Nusantara, Vol. 1 (Jakarta: CV Haji Masagung, 1992), 1st ed., 69.

${ }^{5}$ Afina Izzati, "Nilai-nilai Konstruk Harmoni Perspektif Tokoh Wayang Semar," FIKRAH, Vol. 4, No. 2 (2017): 261, https://doi.org/10.21043/fikrah.v4i2.1631.

${ }^{6}$ Oke Setiawan, I Made Kartika Dhiputra, dan Ni Nyoman Sudiani, "Nilai-Nilai Filosofis dalam Karakter Tokoh Wayang Semar Perspektif Pendidikan Masyarakat Hindu Jawa di Pringsewu Lampung," Jurnal Pasupati, Vol. 5, No. 1 (2018): 104-124.
} 
Rudy Al-Hana \& M. Yusuf: Nilai-nilai Sufistik Tokoh Wayang Semar dan Implikasinya terhadap Pendidikan Islam

Javanese Society." Artikel yang ketiga ini juga memiliki kesamaan dengan artikel pertama dan kedua, yakni sama-sama membahas nilai filofofis yang ada pada diri Semar dan merupakan manifestasi dari karakter masyarakat Jawa. ${ }^{7}$ Dan keempat, artikel yang ditulis oleh Bakhrudin All Habsy dengan judul "Semar Puppet Counseling Model" yang mana artikel ini mencoba mengelaborasi nilai-nilai kehidupan Semar menjadi sebuah teknik konseling. ${ }^{8}$

Dari kesemua artikel yang telah dibahas dalam penelitian sebelumnya kebanyakan menggali nilai-nilai filosofis yang ada pada diri Semar untuk pengembangan pribadi. Sedangkan dalam artikel ini, penulis mencoba menganalisis dan mengelaborasi nilai-nilai sufistik yang tergambar dari tokoh wayang Semar serta implikasinya terhadap pendidikan Islam. Ada satu artikel yang membahas tentang Semar dan nilai pendidikan yang dihasilkannya, yakni artikel yang ditulis oleh Didi Yulistio dan Agus Joko Purwadi dengan judul "Study on Structure and Values Education In Stories Wayang Kulit." Namun, dalam artikel ini tidak spesifik membahas nilai sufistik tokoh wayang Semar, melainkan membahas tentang satu episode kehidupan Semar dalam lakon "Semar Mbangun Kahyangan.",

Untuk menjawab masalah di atas, penulis menggunakan metode penelitian studi teks, atau dalam istilah lain disebut dengan penelitian kualitatif dengan jenis studi kepustakaan -library research, yakni penelitian yang fokus pada telaah, kajian, dan pembahasan literatur klasik maupun kontemporer. Dalam katagori studi teks, diistilahkan oleh Rorty, Cheneewind, dan Skinner sebagai rekonstruksi rasional dan historis -rational and historical reconstructive. ${ }^{10}$ Maksud dari rational reconstructive ialah, ide dianggap sebagai gagasan dalam sejarah, sedang, tek-teks dikumpulkan sebagai dokumen sejarahnya, sama halnya dengan pengistilahan sumber data penelitian, yaitu sumber data primer dan sumber data sekunder.

\footnotetext{
${ }^{7}$ Nanik Herawati, D B Putut Setiadi, and Erry Pranawa, "Figure Of Semar In The Javanese Puppet Story as a Symbol of Character Building in the Javanese Society," in Literature, Tourism, and Multicultural Education in The Industrial Era 4.0, Vol. 1, 1 (29th International Conference On Literature And Hiski 36th Anniversary In Gorontalo 2020, Gorontalo: Gorontalo State University, 2021), 6.

${ }^{8}$ Bakhrudin Al-Habsy, "Semar Puppet Counseling Model," COUNS-EDU: The International Journal of Counseling and Education, Vol. 2, No. 1 (2017): 19, https://doi.org/10.23916/002017024410.

${ }^{9}$ Didi Yulistio \& Agus Joko Purwadi, "Study on Structure and Values Education in Stories Wayang Kulit," in Semirata, Vol. 1, 1 (International Seminar and Annual Meeting BKS-PTN Wilayah Barat, Palembang: Sriwijaya University, 2018), 136-45.

${ }^{10}$ Richard Rorty, J.B. Cheneewind, and Quentin Skinner, Philosophy in History (Cambridge: Cambridge University Press, 1984).
} 
Sumber data primer dalam penelitian ini ialah segala referensi, artikel, atau literatur tentang tokoh wayang Semar dan ajarannya, sedangkan sumber data sekundernya ialah segala referensi, artikel, atau literatur yang membahas masalah sufisme. Penggalian data dalam penelitian ini menggunakan metode dokumentasi, kemudian dianalisis dengan metode deskriptif content analysis yang berlangsung dengan beberapa tahapan -dimulai dari memilih, membandingkan, menggabungkan, dan memilah berbagai makna dari temuan yang relevan. ${ }^{11}$

\section{B. Mengenal Semar: Sang Mursyid}

Semar cukup dikenal dalam kehidupan masyarakat Indonesia, ia tergolong tokoh pewayangan yang unik dan memiliki nilai-nilai luhur. Ialah Sunan Kalijaga yang menambah figur punakawan empat -Semar, Nala Gareng, Petruk, dan Bagong- dalam cerita pewayangan, guna dalam rangka misi dakwah penyebaran agama Islam. Tokoh Semar tidak akan ditemukan dalam epos Ramayana, Mahabarata, dan Barathayuda di India. $^{12}$

Asal-usul Semar dalam mitos Jawa diceritakan terdapat dua versi. Pertama, surga -langit- dan bumi dikuasai oleh Sang Hyang Wenang, ia berputerakan satu, Sang Hyang Tunggal, yang kemudian memperistri Dewi Rekawati -putri dari kepiting raksasa yang bernama Rekatama. Dewi Rekawati kemudian bertelur dan telur tersebut terbang menghadap Sang Hyang Wenang. Setiba di hadapan Sang Hyang Wenang, telur tersebut menetas dan berwujud 3 (tiga) makhluk antromorfis. ${ }^{13}$ Dari kulit telur muncul Tejamantri; dari putih telur muncul Ismaya; dan dari kuning telur muncul Manikmaya.

${ }^{11}$ Ahmad Rijali, “Analisis Data Kualitatif," Alhadharah: Jurnal Ilmu Dakwah, Vol. 17, No. 33 (2019): 81, https://doi.org/10.18592/alhadharah.v17i33.2374; Carl F. Auerbach and Louise B. Silverstein, Qualitative Data: An Introduction to Coding and Analysis, Qualitative Studies in Psychology (New York: New York University Press, 2003); Cynthia A. Lietz and Luis E. Zayas, "Evaluating Qualitative Research for Social Work Practitioners," Advances in Social Work 11, no. 2 (September 28, 2010): 188-202, https://doi.org/10.18060/589.

${ }^{12}$ Sindung Tjahyadi, "Dekonstruksi Pemahaman Budaya Jawa tentang Hakikat dan Hubungan Kawula-Gusti pada Lakon Wayang Semar Kuning,” Jurnal Filsafat, Vol. 19, No. 2 (2009): 23.

${ }^{13}$ Istilah antromorfis diambil dari bahasa Yunani, yakni anthropos yang berarti manusia dan morphe yang berarti bentuk. Maka dapat diambil pengertian bahwa antromorfis/antromorfik ialah segala sesuatu yang berkaitan dengan bentuk manusia. Semar sekilas memiliki bentuk yang sama dengan manusia, sehingga ia tergolong makhluk antromorfis. Lihat dalam Ranang Agung Sugihartono, "Antromorfisme dalam Kesenian Indonesia," Capture: Jurnal Seni Media Rekam, Vol. 2, No. 2 (2011): 31. 
Rudy Al-Hana \& M. Yusuf: Nilai-nilai Sufistik Tokoh Wayang Semar dan Implikasinya terhadap Pendidikan Islam

Kemudian Sang Hyang Wenang mengganti nama mereka, Tejamaya menjadi Togog, Ismaya menjadi Semar, dan Manikmaya menjadi Bathara Guru. ${ }^{14}$

Kedua, diceritakan, Sang Hyang Wenang memegang telur dan menetas dengan sendirinya, disertai dengan tempaknya langit, bumi, cahaya (Teja), serta dua makhluk antromorfis yaitu Manik dan Maya. Tranformasi dari Maya -sang putih telurdinamakan Semar dan ditugaskan untuk memelihara dan melindungi bumi. Kemudian transformasi dari Manik -sang kuning telur- dinamakan Bathara Guru sebagai raja para Dewa di surga (langit). ${ }^{15}$

Keunikan dari sosok Semar didukung oleh perawakannya yang tampak ndeso, buruk rupa, dan tidak menunjukkan kehebatan sama sekali. Namun dengan perawakannya yang seperti itu, nilai yang terkandung di dalamnya dapat dikatakan sangat luhur. Dalam seni kriya wayang kulit purwa gagrak Surakarta, Semar diceritakan memiliki lima wanda -bentuk yang menggambarkan sikap dan suasana batin, yaitu mega, dunuk, mbrebes, ginuk, dan miling. Sedangkan dalam gagrak Yogyakarta, Semar diceritakan memiliki wanda miling dan mbrebes untuk adegan jejer; wandah dukun untuk adegan rembangan; dan wanda dunuk untuk adegan perang. ${ }^{16}$ Rambut Semar berbentuk kuncung yang maknanya akuning sang kuncung (menganggap diri sebagai pelayan). ${ }^{17}$ Sepertihalnya bentuk kuncung, wayang-wayang selain Semar juga dapat dicermati bagian tubuhnya dengan sebutan candra-panca. Candra-panca adalah 5 (lima) aspek penentu dalam objek wayang purwa, seperti: netra (liyepan, kedhelen, peten, thelengan, plelengan, penanggalan), netya (sumeh, someg, soma, sumengah, samun), wanda (ruruh, sereng, sirung, serang, sarang), dedegpengadeg (pidekso, prakoso, ngropek, ngropoh, ngripik) dan solah-bowo (cakep, cukup, cikat, cakut, cakcek). ${ }^{18}$

Hal yang menarik juga dari pribadi Semar, jika diperinci akan ditemukan sebagai berikut: pertama, tubuh Semar yang bulat melambangkan bumi tempat tinggal

\footnotetext{
${ }^{14}$ Jati Nurcahyo, "Makna Simbolik Tokoh Wayang Semar dalam Kepemimpinan Jawa,” Jurnal Media Wisata, Vol. 16, No. 2 (2018): 1069-1076 https://doi.org/10.36276/mws.v16i2.265.

${ }^{15}$ Wisma Nugraha Christianto Rich, "Peran dan Fungsi Tokoh Semar-Bagong dalam Pergelaran Lakon Wayang Kulit Gaya Jawa Timuran,” Humaniora, Vol. 15, No. 3 (2003): 286-301.

${ }^{16}$ Bambang Hasrinuksmo, et. al., Ensiklopedi Wayang Indonesia (Jakarta: Sekretariat Nasional Pewayangan Indonesia, 1999).

${ }^{17}$ Muhammad Zaairul Haq, Tasawuf Semar Hingga Bagong, Simbol, Makna, dan Ajaran Makrifat dalam Panakawan (Yogyakarta: Kreasi Wacana, 2009).

${ }^{18}$ Keterangan lebih lanjut lihat dalam: Nurhadi Siswanto, "Filosofi Kepemimpinan Semar," Panggung, Vol. 29, No. 3 (2019), https://doi.org/10.26742/panggung.v29i3.1011.
} 
makhluk di dunia; kedua, tangan kanan ke atas perlambang pemujian Sang Maha Tunggal, sedang tangan kiri ke bawah perlambang perserahan diri yang maksimal, keilmuan yang netral namun simpatik; ketiga, Semar selalu tersenyum namun mata sembab, perlambang suka dan duka; keempat, wajah tua namun cukuran kuncung anak kecil, perlambbang tua dan muda; kelima, Semar berkelamin laki-laki namun berpayudara, perlambang pria dan wanita; keenam, Semar inkarnasi dewa namun membaur dengan rakyat, postur berdiri namun tampak jongkong, perlambang atasan dan bawahan, bersatunya yang profan dengan yang sakral, manunggal kawula lawan Gusti; ketujuh, Semar berjalan menghadap ke atas, perlambang selalu menghadap Sang Pencipta -Sang Khaliq; kedelapan, ucapan spesial Semar yaitu mbergegeg ugeg-ugeg, hmel-hmel, sak ndulit langgeng, perlambang yang "daripada diam (mbergegeg), lebih baik berusaha untuk lepas (ugeg-ugeg), dan mencari makan (hmel-hmel), walaupun hasilnya sedikit (sak ndulit), tapi akan terasa abadi (langgeng)."19

Semar merupakan perwujudan dari seimbangnya alam dan manusia karena kemunculan Semar secara simbolik sebagai pembenah gara-gara -huru-hara/keadaan disharmoni. Secara normatif keadaan disharmoni dapat diatasi oleh Semar karena ia memiliki sifat rendah diri - andhap ashor; kehidupan cukup tapi berperilaku sederhana samadya; dan penyeimbang ligkungan hidup -baik lingkungan sosial maupun lingkungan fisik. ${ }^{20}$ Semar juga memiliki watak sabar, jujur, ramah, suka humor, sederhana, tenang, rendah hati, tulus dan tidak munafik. ${ }^{21}$ Lebih lanjut, dalam tradisi Jawa, Semar disebut Badranaya -Bodronoyo. Bebadra mempunyai arti membangun sarana dari dasar, sedangkan Naya atau Nayaka mempunyai arti sebagai utusan -rasul. Jika dua kata tersebut digabungkan, nama Badranaya bisa berarti sebagai seseorang yang mengemban perintah Tuhan demi terciptanya kehidupan kebaikan manusia. ${ }^{22}$ Dapat disimpulkan bahwa sosok Semar adalah seorang abdi yang setia, pamomong, penasihat spiritual, teman bercengkrama dan penghibur pada saat permasalahan hadir pada diri seseorang.

\footnotetext{
${ }^{19}$ Nora Yuniar Setyaputri, "Karakter Ideal Konselor Multibudaya Berdasarkan Nilai Luhur Semar," Jurnal Kajian Bimbingan dan Konseling, Vol. 2, No. 2 (2017): 58-65, https://doi.org/10.17977/um001v2i22017p058.

${ }^{20}$ Sindung Tjahyadi, "Dekonstruksi Pemahaman..."

${ }^{21}$ Sekar Restika Wibowo \& Tuti Hardjajani, "Kajian Nilai Bimbingan pada Tokoh Pewayangan Semar," CONSILIUM : Jurnal Program Studi Bimbingan dan Konseling, Vol. 3, No. 1 (2015): 7

${ }^{22}$ Margono Notopertomo \& Warih Jatirahayu, 51 Karakter Tokoh Wayang Populer (Klaten: PT. Hafamira, 2012).
} 
Juga, Semar adalah panakawan yang misterius, selain sebagai pamong juga sebagai pengayom. Semar atau Juru Dyah Prasanta pertama kali dikenal dari kitab Gathutkaca Sraya, karangan Empu Panuluh sebagai seorang abdi yang bertugas menghibur bendara. ${ }^{23}$ Semar yang merupakan jelamaan dari Ismaya, rela turun di madyapada hanya untuk menjadi pamong para satria agung. Betapapun hebatnya kesatria, namun masih membutuhkan wejangan dari Semar Badrayana. Semar adalah figur yang waskita, yakni ngerti sakdurunge winarah -tahu sebelum terjadi. Kiai Semar juga tahu peta sosiokultural di triloka -tiga dunia- yaitu dewata, raksasa, dan manusia. Jagad gumelar -makro kosmos- dan jagad gumulung -mikro kosmos- keduanya mendapat pengawalan ketat dari Semar. ${ }^{24}$

Semar dengan tulus ikhlas menjadi pamomong satria-satria utama, sejak Begawan Manumayasa hingga anak keturunannya. Unsur-unsur kebatinan dan corak sifat Semar di atas merupakan sebuah indikasi bahwa Semar telah mencapai rasa jati; jati rasa. Rasa jati dalam bahasa tasawuf adalah pencapaian pada maqam makrifat, yaitu pribadi yang benar-benar tahu kesejatian hidup. ${ }^{25}$

\section{Nilai Sufistik Semar}

Sufistik mengarah kepada perilaku yang bersifat dan beraliran sufi. Kemudian sufi merupakan laku seseorang yang memahami dan menjalankan tasawuf, ${ }^{26}$ atau lebih singkatnya Harun Nasution menyebut sufi sebagai ahli ilmu suluk atau tasawuf. ${ }^{27}$ Tasawuf sendiri memiliki definisi sebagai ilmu yang mempelajari tentang cara agar mendekatkan diri kepada Tuhan yang Maha Kuasa (Allah SWT) ${ }^{28}$ Dalam literatur

${ }^{23}$ Purwadi, Mengkaji Luhur Tokoh Semar (Yogyakarta: Kanwa Publisher, 2014).

${ }^{24}$ Ibid., 9.

${ }^{25}$ Ibid., 8.

${ }^{26}$ Tim Penyusun Kamus Bahasa Indonesia, Kamus Bahas Indonesia (Jakarta: Pusat Bahasa, 2008), 1382.

\footnotetext{
${ }^{27}$ Harun Nasution, Filsafat..., 34.
}

${ }^{28}$ Mengenai akar kata tasawuf, ada yang mengatakan ia berasal dari masdar -kata bendatashawwafa, yatashawwafu, tashawwufan, yang secara etimologi berarti pakaian yang berasal dari bulu domba. Sebagian lagi menyatakan bahwa tasawuf berasal dari kata "shafa" yang berarti suci, jernih, dan bersih. Lanjut lagi ada yang mengatakan berasal dari kata "shuffah" yang mengacu kepada para sahabat Muhajirin yang tinggal di serambi Masjid Nabawi. Kemudian juga ada yang mengatakan berasal dari kata "shufanah" yakni nama sejenis kayu di padang pasir. Dan ada yang mengatakan bahwa ia berasal dari bahasa Yunani "theosofi" yang berarti ilmu ketuhanan. Lihat Abu Bakar Aceh, Pengantar Sejarah Sufi Dan Tasawuf (Solo: Romadhoni, 1990). 
barat, tasawuf dikenal dengan sebutan Islamic mysticism atau Islamic esoteric, ${ }^{29}$ yang mana keduanya bisa berlaku sebagai doktrin atau praktik keagamaan.

Tasawuf sebagai doktrin keagamaan mengacu kepada pandangan sufi tentang realitas yang berasal dari ajaran kitab suci, dan telah diperkuat juga diadaptasi oleh pemahaman generasi guru-guru setelahnya. Hal ini memberikan peta kosmos yang memungkinkan manusia untuk memahami situasi mereka sehubungan dengan Tuhan. Realitas yang dimaksud dalam doktrin tasawuf ialah isi dari shahadah atau pengakuan (Tidak ada) selain Tuhan, yang membedakan antara Yang Nyata dan yang tidak nyata; antara Yang Mutlak dan relatif; atau antara Tuhan dan "segala sesuatu selain Tuhan." Secara tradisional shahadah dibagi menjadi dua bagian, pertama, negasi "tidak ada tuhan" dan kedua, penegasan "kecuali Tuhan." Babak pertama menyangkal realitas yang melekat di dunia dan diri. Babak kedua menegaskan ultimasi realitas ilahi. Shahadah berarti bahwa "tidak ada pencipta selain Tuhan," "tidak ada yang berbelas kasih selain Tuhan," "tidak ada yang tahu selain Tuhan." Singkatnya, itu berarti bahwa "tidak ada realitas selain Tuhan."30

Sedangkan tasawuf sebagai praktik keagamaan mengarah seperti halnya keyakinan sufi yang berakar pada shahadah. Karena itu ia menggabungkan dua perspektif yang saling melengkapi -negasi dan afirmasi, atau "tidak ada Tuhan" dan "kecuali Tuhan." Praktik tasawuf memerlukan proses transformasi batin di mana kekuatan jiwa dialihkan kepada Tuhan. Sufisme menambah banyak praktik spiritual dalam banyak praktik syariat. ${ }^{31}$

Genealogi di atas sejalan dengan praktik sufi yang diajarkan oleh Semar. Semar, sang pengayom, secara implisit digambarkan mempunyai arti ilahi karena Semar banyak disebut sebagai kawula pinanditha -kawula yang dianggap seperti pendheta. Prabu Kresna, seorang raja dari Dwarawati juga memperlakukan semar dengan sangat santun, saran-saran Kiai Semar juga selalu menjadi pertimbangan dalam mengambil keputusan yang penting. ${ }^{32}$

\footnotetext{
${ }^{29}$ William C. Chittick, Sufism: A Beginner's Guide, Beginner's Guides (London: Oneworld, 2008).

${ }^{30}$ Samsul Munir Amin, Ilmu Tasawuf (Jakarta: Amzah, 2012), 15.

${ }^{31}$ D. Zohar \& I. Marshal, Spiritual Intellegence: $S Q$ The Ultimate Intelligence (London: Bloomsburry Publishing, 2001).

${ }^{32}$ Darmoko, "Moralitas Jawa dalam Wayang Kulit Purwa: Tinjauan pada Lakon Laire Semar," Paradigma, Jurnal Kajian Budaya, Vol. 5, No. 2 (2016): 118, https://doi.org/10.17510/paradigma.v5i2.52.
} 
Rudy Al-Hana \& M. Yusuf: Nilai-nilai Sufistik Tokoh Wayang Semar dan Implikasinya terhadap Pendidikan Islam

Lebih rinci, Semar mengajarkan beberapa tingkat atau jalan panjang yang harus ditempuh oleh manusia yang sedang berusaha menuju ke hadirat Ilahi, tepatnya ada 5 (lima) jalan yang diajarkan oleh Semar, yaitu: pertama: syariat atau sembah raga, kedua: tarekat atau sembah kalbu, ketiga: hakekat atau sembah jiwa, keempat: makrifat atau sembah rasa, dan kalau keempat tingkat itu sudah dilaksanakan dengan sempurna maka sampailah ke tingkat kelima, yaitu tingkat mahabbah atau cinta suci (asmarasanta). ${ }^{33}$

Bagan 1: Tahapan ke hadirat Ilahi prespektif Semar

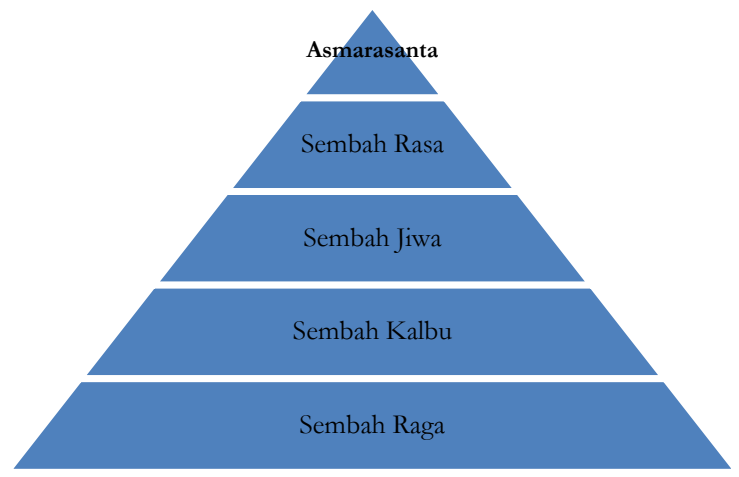

Jika ditelisik secara mendalam, ajaran Semar mengenai laku -tahapan menuju Ilahi, sejalan dengan karakteristik tasawuf amali. Amali berarti bentuk-bentuk perbuatan, yaitu sejenis laku-laku untuk menempuh perjalanan spiritual. Dalam tasawuf amali ada 4 (empat) fase yang harus dilewati, pertama, syariat, yakni amalan dhahir formal yang telah ditetapkan oleh Tuhan dalam ajaran agama. Kedua, thariqat, yakni seperangkat serial moral yang menjadi pegangan ahli sufi yang dijadikan metoda pengarahan jiwa dan moral. Ketiga, hakikat, kemampuan ahli sufi dalam merasakan dan melihat kehadiran Tuhan dalam melaksanakan syariat. Keempat, makrifat, pengenalan Tuhan secara langsung dari hati sanubari sebagai hikmat menjalankan tiga hal sebelumnya. $^{34}$

Selanjutnya, pembentukan manusia menuju ke hadirat Ilahi yang diajarkan oleh Semar menekankan pada aspek spiritual. Di mana substansi kehidupan tidak akan lengkap jika domain jiwa belum mampu dekat dengan Sang Pencipta. Kehidupan sufi tersebut bisa dilakukan secara pribadi/individual atau dengan cara kolektif. ${ }^{35}$

\footnotetext{
${ }^{33}$ Purwadi, Mengkaji...

${ }^{34}$ Hamka, Tasawuf Perkembangan dan Pemurniannya (Jakarta: Republika, 2016), 78.

${ }^{35}$ Suriadi, "Pendidikan Sufistik Tarekat Qadiriyyah wa Naqsyabandiyyah (Kajian atas Pemikiran Ahmad Khatib Sambas)," Khazanah: Jurnal Studi Islam dan Humaniora, Vol. 15, No. 2 (2018): 263, https://doi.org/10.18592/khazanah.v15i2.1899.
} 
Melaksanakan kehidupan sufi dengan cara pribadi/individual adalah mengamalkan sifatsifat sufistik, seperti rasa eling, sahid atau asetik atau pertapa, sabar, dan ridha atau ikhlas. ${ }^{36}$ Lagi-lagi, jika ditelisik secara substantif akan menemukan kesamaan dengan tasawuf akhlaqi, Tasawuf akhlaqi merupakan suatu ajaran yang membahas tentang kesempurnaan jiwa yang diformulasikan pada pengondisian sikap mental yang ketat, guna mencapai titik kebahagiaan yang optimal. ${ }^{37}$

Rasa eling mengacu kepada kesadaran yang paling dalam (sejati). Rasa eling ini nanti yang melindungi manusia dari godaan dan bencana. Paling penting di sini, di mana yang berkisar sebagai alat bantu dalam menanamkan rasa eling, yaitu "zikir" (dzikir), yang diperintahkan Tuhan kepada manusia untuk dilakukan dalam banyak hal. Sahid atau asetik atau pertapa yaitu meninggalkan segala hal tentang keduniaan, drajat, pangkat, dan menyepikan diri dengan tujuan untuk menentramkan jiwa. Sahid atau asetik atau pertapa yang diajarkan oleh Semar dimulai dengan taubat dan dibarengi dengan laku zuhud, serta menjalani kehidupan fakir dan prihatin. ${ }^{38}$ Sabar mengarah kepada kepatuhan dalam menjalankan segala perintah Tuhan, sedangkan ridha atau ikhlas mengarah kepada usaha yang tidak menentang ketetapan Tuhan. ${ }^{39}$

Para sufi mengatakan bahwa untuk sampai pada sikap mental yang kuat tersebut seseorang harus mengosongkan diri dari segala sifat tercela dan keduniaan, atau yang sering disebut dengan takhalli. Kemudian mengisi dengan sifat-sifat terpuji dengan taat lahir dan batin, atau yang sering disebut dengan tahalli. Disusul dengan penampakan diri Tuhan pada individu yang sukses melaksanakan dua hal di atas, atau yang sering disebut dengan tajalli. ${ }^{40}$ Tidak hanya tiga hal tersebut, ada juga yang menambah tiga tahapan lagi untuk sampai pada laku -tahapan menuju Ilahi, yaitu munajat-melaporkan segala sesuatu kepada Tuhan; muraqabah -selalu merasa dekat, berhadapan, dan diawasi oleh Tuhan; dan muhasabah -meyakini bahwa Tuhan mengetahui fikiran, perbuatan, dan rahasia hati sehingga selalu menganalisis apa yang dilakukan. ${ }^{41}$

${ }^{36}$ Purwadi, Mengkaji...

${ }^{37}$ Mahjudin, Kuliah Akhlak Tasawuf (Jakarta: Kalam Mulia, 1991).

${ }^{38}$ Afina Izzati, "Nilai-nilai Konstruk..."

${ }^{39}$ Purwadi, Mengkaji...

${ }^{40}$ Ismail Hasan, "Tasawuf: Jalan Rumpil Menuju Tuhan," An-Nuha, Vol. 1, No. 1 (2014): 20; Artani Hasbi, "Hakikat Kebenaran Mengkaji Tasawuf Akhlaki - Akhlak Kenabian," MISYKAT: Jurnal Ilmu-ilmu Al-Quran, Hadist, Syari'ah dan Tarbiyah, Vol. 1, No. 2 (2016): 43, https://doi.org/10.33511/misykat.v1n2.43.

${ }^{41}$ Abuddin Nata, Ilmu Kalam, FIlsafat, dan Tasawuf "Dirasah Islamiyah IV" (Jakarta: PT. Raja Grafindo, 2011), 153-155; Muhammad Fethullah Ghulen Ghulen, Tasawuf Untuk Kita Semua (Menapaki Bukit-Bukit Zamrud Kalbu Melalui Istilah-Istilah dalam Prespektif Sufisme) (Jakarta: Republika, 2014), 117-119. 
Rudy Al-Hana \& M. Yusuf: Nilai-nilai Sufistik Tokoh Wayang Semar dan Implikasinya terhadap Pendidikan Islam

Setelah menerangkan tentang tasawuf akhlaqi dan tasawuf amali, masih ada satu kerakteristik tasawuf yang tersisa, yakni tasawuf falsafi. Tasawuf falsafi yaitu tasawuf yang memadukan antara visi intuitif dengan visi rasional. ${ }^{42}$ Falsafi diambil dari filosofi tokoh yang mengembangkannya. Dalam hal ini Semar menggagas tentang ajaran "manunggaling kawulo lawan Gusti." Ajaran ini diwejangkan oleh Semar dalam Lakon Semar Boyong, yang isinya kurang lebih sebagai berikut:

Sayektosipun kenging kinarya cihna manunggaling kawula lawan gusti, pamong kaliyan ingkang kedah dipun mong, kanthi manunggal kasebut badhe ageng dayanipun, wewangunan pambanguning nagari saya badhe lancar. Lan badhe langkung raket supeket manunggaling kawula gusti, kanthi sesanti hayu rahayu ingkang tinemu, ayem tentrem adil lan makmur. (Sesungguhnya dapat dijadikan contoh sebagai bentuk manunggaling kawula gusti, antara Penjaga dengan yang dijaga, dengan manunggal tersebut akan besar daya kekuatannya, pembangunan negeri akan semakin lancar. Semakin kuat persatuan manunggaling kawula gusti, dengan semboyan selamat, tentram adil dan makmur. ${ }^{43}$

Satu sisi, wejangan tersebut mengindikasikan tentang peran penguasa dengan rakyat. Di sisi yang lain, mengindikasikan peran Tuhan dengan hambanya. Dalam tasawuf falsafi ini memang bukan semata didapat dengan akal, tetapi dengan batinnya batin. Sedang orang awam menyebutnya, "ilmu kebatinan.” Kiai Semar selain memiliki kekuatan fisik, ia juga memiliki kekuatan batin yang dalam ideom orang Jawa semar dikenal memiliki kadigdayan atau kesekten. Kadigdayan atau kasekten yang diajarkan oleh Semar mengandung 4 (empat) unsur penting, yaitu pertama, budi pekerti luhur; amal shalih; moral; dan akhlak atau filsafat tingkah laku. ${ }^{44}$ Kedua, Sangkan paraning dumadi atau filsafat tentang "ada" (kawruh "Hono," The Philosophy of Being, the Science of Being atau Ontology). Ketiga, ilmu gaib atau Jaya kawijayan atau kanuragan atau Okultisme. Keempat, Manunggaling kawula Gusti atau mistikisme atau tasawuf. ${ }^{45}$

Dekonstruksi pemaknaan hubungan manunggaling kawula lawan Gusti pada satu sisi berbeda dengan perspektif pemahaman Agama Ibrahim yang memahami

\footnotetext{
${ }^{42}$ Abrar M. Dawud Faza, "Tasawuf Falsafi," Al-Hikmah: Jurnal Theosofi Dan Peradaban Islam, Vol. 1, No. 1 (2019): 56-70; Syafwan Rozi, "Wacana Sufistik: Tasawuf Falsafi di Nusantara Abad XVII M: Analisis Historis dan Filosofis," Islam Realitas: Journal of Islamic \& Social Studies, Vol. 3, No. 2 (2017): 169, https://doi.org/10.30983/islam_realitas.v3i2.405; U. Abdurrahman, "Metodologi Tafsir Falsafi dan Tafsir Sufi," 'Adliya, Vol. 9, No. 1 (2015): 24.

${ }^{43}$ Dwijo Carito, Lampahan Semar Boyong (Surakarta: Cendrawasih, 2013), 13; A. Wahyudi, Bersatu Manunggaling Kawula Gusti (Jogjakarta: DIVA Press, 2014), 23. 2nd ed., 45 .

${ }^{44}$ Sri Mulyono, Wayang Dan Filsafat Nusantara, Vol. 2, 2 (Jakarta: CV Haji Masagung, 1992),

${ }^{45}$ Suteja, Sufisme Lokal Mencari Akar Tradisi Tasawuf Indonesia (Cirebon: Pangger Publishing, 2016), 156 .
} 
realitas makhluk dan Tuhan dalam perspektif dualisme, namun pada sisi lain ia melestarikan dan memelihara hasrat penyatuan pemahaman manusia ke dalam Yang Mutlak yang akarnya terdapat dalam tradisi pra-Islam yang mengenal gagasan inkarnasi dan reinkarnasi. Dalam dimensi metafisis ini, bolehlah Semar dinyatakan sebagai simbol pencarian orang Jawa atas sangkan paraning dumadi (asal mula dan tujuan segala yang ada) dan dumadine sangkan paran (hadirnya Tuhan sebagai sumber dan asal mula kehidupan). ${ }^{46}$

Tasawuf ini dikatakan sebagai tasawuf falsafi karena kaya akan pemikiranpemikiran filsafat. Ajaran filsafat yang digunakan adalah emanasi neo-platonisme. Dinamakan falsafi karena sudah memasuki ranah ontologi (ilmu kaun) yaitu hubungan Tuhan dengan alam semesta. Dengan demikian wajarlah jika ajaran Semar berbicara tentang emanasi (faidh), inkarnasionime (hulul), persatuan manusia dengan Tuhan (ittihad), dan keesaan (wahdah). ${ }^{47}$ Hampir Sama dengan ajaran Al-Hallaj dan Syekh Siti Jenar.

Berikut tabel tentang nilai-nilai sufistik yang diajarkan oleh Kiai Semar:

Tabel 1: Karakteristik Tasawuf Perspektif Tokoh Wayang Semar

\begin{tabular}{llc}
\multicolumn{1}{c}{ Tasawuf Amali } & \multicolumn{1}{c}{ Tasawuf Akhlaqi } & Tasawuf Falsafi \\
\hline 1. Sembah raga & 1. Rasa eling, & "Manunggaling kawulo \\
2. Sembah kalbu & 2. Sahid atau asetik atau & lawan Gusti." \\
3. Sembah jiwa & pertapa, & \\
4. Sembah rasa & 3. Sabar, dan & \\
5. Asmarasanta & 4. Ridha atau ikhlas & \\
\hline
\end{tabular}

Setelah manusia dapat melaksanakan tingkat-tingkat tarekat dan hakekat -tiga jenis karakteristik tasawuf di atas- secara sempurna, maka barulah manusia sampai ke tingkat makrifat yaitu arif-wicaksana, sudah dapat menerima dan mengetahui pengetahuan illahi/janabhadra (sinar pengetahuan), dan kemudian sampai ke tingkat mahabbah, yaitu cinta kasih suci (asmarasanta) sebagai sarana menerima asmarasantaNya dan bersatu dengan-Nya. Al-fana dan al-baqa, atau -mati raga, yaitu menghilangkan sifat manusia -the passing away of his phenomenal existence atau mati jroning urip. Karena kemauan yang keras dan suci, maka hijab dibuka oleh-Nya dan dengan mata hati sanubari bertemu dengan Tuhan dan melihat Ia pada wajah-Nya

\footnotetext{
${ }^{46}$ Sindung Tjahyadi, "Dekonstruksi Pemahaman..."

${ }^{47}$ Purwadi, Mengkaji...
} 
Rudy Al-Hana \& M. Yusuf: Nilai-nilai Sufistik Tokoh Wayang Semar dan Implikasinya terhadap Pendidikan Islam

sebagai cahaya buana. Dan yang terakhir, yakni ittihad/mystical union (manunggal) dan berdialog. 48

\section{Implikasi Nilai Sufistik Semar terhadap Pendidikan Islam}

Setiap negara telah menjamin pendidikan bagi warganya, termasuk negara berkembang seperti Indonesia. Selain itu, adanya pendidikan dimaksudkan untuk mengembangkan kompetensi diri bagi setiap individu yang hidup di suatu negara tersebut ${ }^{49}$. Hal ini sejalan dengan tujuan pendidikan nasional yang dijelaskan dalam Undang-Undang (UU) Republik Indonesia (RI) nomor 20 tahun 2003 Bab II pasal 3 tentang Sistem Pendidikan Nasional bahwa:

Pendidikan nasional berfungsi mengembangkan kemampuan dan membentuk watak serta peradaban bangsa yang bermartabat dalam rangka mencerdaskan kehidupan bangsa, bertujuan untuk berkembangnya potensi peserta didik agar menjadi manusia yang beriman dan bertakwa kepada Tuhan Yang Maha Esa, berakhlak mulia, sehat, berilmu, cakap, kreatif, mandiri, dan menjadi warga negara yang demokratis serta bertanggung jawab. ${ }^{50}$

Pendidikan adalah sebuah proses pengubahan sikap dan tingkah laku manusia dengan selalu mengembangkan potensi yang ada pada setiap anak didik. ${ }^{51}$ Semua berhubungan dengan manusia, karena tumbuh dan berkembangnya masyarakat yang berbudaya tidak lepas dari pengaruh kehidupan manusia tersebut. Dengan begitu, dalam pendidikan terdapat alih generasi yang mampu mengadakan transformasi nilai-nilai ilmu pengetahuan dan budaya kepada generasi berikutnya agar dapat menatap hari esok yang lebih baik.

Beberapa pakar mendefinisikan pendidikan sebagai berikut, Ki Hajar Dewantara -dalam Suwarno- berpendapat bahwa pendidikan ialah menuntun kodrat manusia agar

\footnotetext{
${ }^{48}$ Tingkat-tingkat tasawuf di atas hampir sama/mirip dijelaskan dalam lakon Dewa Ruci -guru Werkudhara/Bima. Lihat dalam Diwan Diwan, I Nyoman Kiriana, and I Made Sujanayasa, “Ajaran Susila pada Tokoh Bima Lakon Dewa Ruci dalam Pertunjukan Wayang Kulit untuk Meningkatkan Mutu Pendidikan di Abad 21," Adi Widya: Jurnal Pendidikan Dasar, Vol. 4, No. 2 (2019): 151, https://doi.org/10.25078/aw.v4i2.1117; Siti Isnaniah, "Dewa Ruci: Sebuah Alternatif Sistem Pendidikan," LiNGUA: Jurnal Ilmu Bahasa dan Sastra, Vol. 5, No. 1 (2011), https://doi.org/10.18860/ling.v5i1.612.

${ }^{49}$ Marina Dwi Mayangsari, "Motivasi Berprestasi Mahasiswa Ditinjau Dari Penerimaan Orangtua," Jurnal Ecopsy, Vol. 1, No. 1 (2016): 21-27, https://doi.org/10.20527/ecopsy.v1i1.480.

${ }^{50}$ Undang-Undang Republik Indonesia Nomor 20 Tahun 2003 Tentang Sistem Pendidikan Nasional, 2003, https://www.unpad.ac.id/wp-content/uploads/2012/10/UU20-2003-Sisdiknas.pdf.

${ }^{51}$ Kementerian Pendidikan dan Kebudayaan, "KBBI: Kamus Besar Bahasa Indonesia, n.d., https://kbbi.kemdikbud.go.id/entri/pendidikan.
} 
dalam anggota masyarakat ia bisa mendapatkan keselamatan yang setinggi-tingginya. ${ }^{52}$ Sedangkan menurut Marimba, pendidikan ialah bimbingan dan pimpinan secara sadar oleh si pendidik terhadap perkembangan jasmani dan ruhani anak didik agar terbentuk pribadi yang sempurna. ${ }^{53}$

Selanjutnya, pendidikan Islam menurut Arifin adalah proses kependidikan yang progresif menuju kepada perubahan anak didik yang lebih baik berlandaskan nilai-nilai ajaran Islam. ${ }^{54}$ Sedangkan Achmadi memberikan pengertian pendidikan Islam adalah sebuah usaha untuh memelihara dan mengembangkan fithrah manusia untuk terbentuknya manusia seutuhnya -insan kamil. ${ }^{55}$

Pendidikan Islam dan nilai-nilai sufi/tasawuf tidaklah berseberangan, akan tetapi berjalan beriringan saling mempengaruhi. Meminjam istilah Achmadi di atas, bahwa pendidikan Islam diselenggarakan dalam rangkah menghasilkan manusia yang seutuhnya -insan kamil, jika ditinjau dalam nilai-nilai sufistik tokoh wayang Semar, Semar seringkali disebut-sebut dalam dunia pewayangan sebagai tokoh yang mempunyai makna komplit dalam penggambaran kehidupan. Tokoh wayang Semar begitu terkenal dengan pesan moral dan nilai-nilai yang diterapkan dapat menjaga keharmonisan antar umat di dalam kehidupan bermasyarakat yang heterogen. Patut kiranya disimpulkan bahwa representasi dalam insan kamil ialah Semar. ${ }^{56}$

Tidaklah gampang membuat insan kamil dalam proses pendidikan, akan tetapi jika dikaitkan dengan nilai-nilai sufistik/tasawuf, cara-cara atau karakteristik tasawuf yang diajarkan oleh Semar bisa diwujudkan. Sebagaimana nilai sufistik yang diajarkan oleh Semar, tokoh-tokoh yang lain juga menawarkan nilai sufistik yang terbukti bisa digunakan dalam pendidikan Islam, Abu Yazid dengan ittihad-nya, Al-Hallaj dengan hulul-nya, Ibn Araby dengan wahdat al-wujud-nya, dan Al-Ghazali dengan kimiya'-nya.

Implikasi secara filosofis yang tergambar dari insan kamil dan penerapan tasawuf prespektif Semar di atas, sejalan dengan tujuan pendidikan Islam. Dalam kurikulum pendidikan Islam, dijelaskan bahwa tujuan pendidikan Islam ialah:

${ }^{52}$ Hasbullah, Dasar-Dasar Ilmu Pendidikan (Jakarta: PT. Raja Grafindo, 2011).

${ }^{53}$ Abd. Rachman Assegaf, Filsafat Pendidikan Islam (Jakarta: PT. Raja Grafindo, 2011).

${ }^{54}$ Muhammad Ahsan, Sumiyati Sumiyati, and Mustahdi Mustahdi, Pendidikan Agama Islam dan Budi Pekerti, (Jakarta: Pusat Kurikulum dan Perbukuan Balitbang Kemendikbud, 2017), Edisi Revisi, Cetakan ke-4. 2012)

${ }^{55}$ A. Qodri Azizi, Pendidikan (Agama) Untuk Membangun Etika Sosial (Semarang: Aneka Ilmu, ${ }^{56}$ Purwadi, Mengkaji..., 29. 
Rudy Al-Hana \& M. Yusuf: Nilai-nilai Sufistik Tokoh Wayang Semar dan Implikasinya terhadap Pendidikan Islam

Peningkatan potensi spiritual dan membentuk peserta didik agar menjadi manusia yang beriman dan bertakwa kepada Tuhan Yang Maha Esa dan berakhlak mulia. Akhlak mulia mencakup etika, budi pekerti, dan moral sebagai perwujudan dari pendidikan agama. ${ }^{57}$

Tujuan pendidikan Islam di atas menekankan pemerhatian dan perubahan pada aspek akhlak, yang mengantarkan manusia pada rana makrifat dan mahabbah asmarasanta- dengan dipraktekkan dalam kehidupan sehari-hari. Hal ini menambah kejelasan, bahwa penyelenggaraan pendidikan Islam, selain pegetahuan yang didapatkan oleh peserta didik, juga, bagaimana nilai-nilai keislaman -nilai-nilai sufistikbisa tergambar dalam akhlak dan moralitas mereka.

Rasulullah SAW. juga menegaskan bahwa misi kenabian yang ia emban ialah sebagai penyempurna akhlak manusia. Akhlak dan budi pekerti ialah jiwa dari pendidikan Islam. ${ }^{58}$ Pencapaian akhlak yang sempurna merupakan tujuan pendidikan Islam. Disinilah, keterkaitan yang kuat antara pendidikan Islam dengan tasawuf/nilai sufistik. Hakikat dari pendidikan adalah akhlak, baik dan buruknya akhlak, tergantung dari hatinya -sembah kalbu. Kemudian tasawuf adalah ilmu yang berkonsentrasi membahas hati agar selalu tertuju kepada Allah.

Secara pedagogis teoritis, di dalam kurikulum Pendidikan Agama Islam terdapat mata pelajaran pendidikan Islam yang di antaranya meliputi Aqidah, Akhlak, dan Fiqih, yang mana ketiganya manifestasi dari ajaran aqidah, syariat, dan hakikat. Tiga hal itu menjadi kesatuan yang tidak bisa dipisahkan. Tiga hal tersebut juga dijabarkan dalam tasawuf amali prespektif Semar, yang mana Semar mengajarkan sembah raga-syariat; sembah kalbu-tarekat; sembah jiwa-hakekat; sembah rasa-makrifat; dan mahabbah - asmarasanta.

Dalam menciptakan pendidikan Islam yang sesuai dengan pembentukan akhlak, ditemukan dalam kurikulum pendidikan Islam tentang Standar Kompetensi -SK- dan Kompetensi Dasar -KD. SK memuat materi yang harus disampaikan, sedangkan KD mengacu kepada tiga aspek, yakni kognitif, afektif, dan psikomotorik. Aspek afektif sangat kuat dengan unsur nilai tasawuf karena memiliki wilayah kajian yang sama, yakni hati. Dengan begitu, pendidikan Islam yang mengimplikasikan nilai-nilai Nasional.

${ }^{57}$ Undang-Undang Republik Indonesia Nomor 20 Tahun 2003 Tentang Sistem Pendidikan

${ }^{58}$ Muhammad Anas Ma`arif, "Tasawuf Falsafi dan Implikasinya dalam Pendidikan Islam," Jurnal Vicratina, Vol. 3, No. 1 (2018): 1-16. 
sufistik/tasawuf diharapkan peserta didik bisa menghayati dan melaksanakan dalam kehidupan sehari-hari.

Secara praktis, guru memerankan posisi penting dalam pendidikan. Tugas guru dalam pendidikan Islam ialah mendidik dengan mengupayakan pengembangan seluruh potensi -fithrah- anak didik, baik psikomotorik, kognitif, dan afektif. Hal ini sesuai dengan figur Semar sebagai pamong dan sang pengayom. Pendidik hendaknya menyatukan diri dengan peserta didik, -baik secara emosional, spiritual, maupun intelektual, juga, menyatukan diri dengan lingkungan, dan materi belajar, sehingga peserta didik memahami keadaan materi secara teks dan konteks, dan lebih memahami peserta didik dengan menyeluruh. Inilah representasi dari ajaran manunggaling kawula lawan Gusti -bersatunya diri dengan Tuhan. Jika sudah menyatu dengan Tuhan, akan lebih muda menyatu antara seorang pendidik dengan peserta didik untuk berbagai hal kebaikan -proses pendidikan.

Pendidik hendanya juga membersihkan diri dari hal-hal yang tidak pantas dilakukan/dilarang oleh ajaran agama, menjaga kewibawaan -muru'ah, dan menjauhi perkara yang subhat, zuhud, dan amal lain yang dilakukan oleh seorang sufi. Jika hati pendidik bersih, akan lebih mudah dalam mentransfer ilmu, karena ilmu adalah cahaya, dan cahaya Allah tidak akan bisa masuk kepada orang-orang yang bermaksiat/durhaka kepada-Nya. Tidak hanya guru, peserta didik juga diajarkan ikhlas dalam mencari ilmu. Sudah menjadi tugas guru untuk menanamkan sifat ikhlas. Guru harus menanamkan tujuan sebenarnya dari belajar, tidak untuk sombong dan mencaci maki sesama.

Dengan demikian, tujuan akhir pendidikan Islam adalah mewujudkan khalifatullah fi al-ardhl-pemimpin dunia dengan kepribadian yang sempurna. Dengan berbagai aktivitas pendidikan Islam melalui pengembangan akhlak yang direpresentasikan dalam nilai-nilai sufistik bisa mengembangkan bagian dari aspek pribadi manusia.

\section{E. Penutup}

Nilai Sufistik yang diajarkan oleh Semar dimulai dari syariat atau sembah raga; tarekat atau sembah kalbu; hakekat atau sembah jiwa; makrifat atau sembah rasa; dan mahabbah atau cinta suci -asmarasanta. Hal ini mengindikasikan bahwa yang diajarkan Semar sebagaimana karakteristik tasawuf amali. Kemudian Semar juga mengajarkan 
Rasa eling, Sahid atau asetik atau pertapa, Sabar, dan Ridha atau ikhlas; hal ini juga sesuai dengan karakteristik tasawuf akhlaqi. Sedangkan karakteristik falsafi sebagaimana digambarkan oleh Semar dengan ajarannya "manunggaling kawula lawan Gusti."

Sebagai kata penutup, nilai-nilai sufistik yang diajarkan oleh Semar berimplikasi pada pendidikan Islam; lebih tepatnya mengandung implikasi secara filosofis, pedagogis teoritis, dan praksis. Secara filosofis, tujuan tasawuf/sufistik Semar sama dengan tujuan pendidikan Islam, yakni fokus pada akhlak untuk menghasilkan insan kamil. Secara pedagogis teoritis, kurikulum pendidikan Islam dan nilai sufistik Semar merupakan manifestasi dari aqidah, syariat, dan hakikat. Juga, pembentukan akhlak ditemukan dalam kurikulum pendidikan Islam tentang Standar Kompetensi-SK- dan Kompetensi Dasar -KD. SK memuat materi yang harus disampaikan, sedangkan KD mengacu kepada tiga aspek, yakni kognitif, afektif, dan psikomotorik. Aspek afektif sangat kuat dengan unsur nilai tasawuf karena memiliki wilayah kajian yang sama, yakni hati. Sedangkan aspek praksis, guru mengambil peranan peting sebagai pengayom dan pemong sebagaimana peran Semar yang digambarkan dalam banyak cerita pewayangan.

\section{F. Daftar Pustaka}

Abdurrahman, U. "Metodologi Tafsir Falsafi dan Tafsir Sufi." 'Adliya, Vol. 9, No. 1 (2015): 24.

Aceh, Abu Bakar. Pengantar Sejarah Sufi dan Tasawuf. Solo: Romadhoni, 1990.

Ahsan, Muhammad; Sumiyati Sumiyati; dan Mustahdi Mustahdi. Pendidikan Agama Islam dan Budi Pekerti. Jakarta: Pusat Kurikulum dan Perbukuan Balitbang Kemendikbud, 2017. Edisi Revisi. Cetakan ke-4.

Al-Habsy, Bakhrudin. "Semar Puppet Counseling Model." COUNS-EDU: The International Journal of Counseling and Education, Vol. 2, No. 1 (2017): 19, https://doi.org/10.23916/002017024410.

Amin, Samsul Munir. Ilmu Tasawuf. Jakarta: Amzah, 2012.

Assegaf, Abd. Rachman. Filsafat Pendidikan Islam. Jakarta: PT. Raja Grafindo, 2011.

Auerbach, Carl F. \& Louise B. Silverstein. Qualitative Data: An Introduction to Coding and Analysis: Qualitative Studies in Psychology (New York: New York University Press, 2003);

Azizi, A. Qodri. Pendidikan (Agama) untuk Membangun Etika Sosial. Semarang: Aneka Ilmu, 2012.

Chittick, William C. Sufism: A Beginner's Guide, Beginner's Guides. London: Oneworld, 2008. 
Darmoko. "Moralitas Jawa dalam Wayang Kulit Purwa: Tinjauan pada Lakon Laire Semar." Paradigma, Jurnal Kajian Budaya, Vol. 5, No. 2 (2016): 118, https://doi.org/10.17510/paradigma.v5i2.52.

Diwan, I Nyoman Kiriana, and I Made Sujanayasa. "Ajaran Susila pada Tokoh Bima Lakon Dewa Ruci dalam Pertunjukan Wayang Kulit untuk Meningkatkan Mutu Pendidikan di Abad 21." Adi Widya: Jurnal Pendidikan Dasar, Vol. 4, No. 2 (2019): 151. https://doi.org/10.25078/aw.v4i2.1117.

Dwijo Carito, Lampahan Semar Boyong (Surakarta: Cendrawasih, 2013), 13;

Faza, Abrar M. Dawud. "Tasawuf Falsafi." Al-Hikmah: Jurnal Theosofi Dan Peradaban Islam, Vol. 1, No. 1 (2019): 56-70.

Ghulen, Muhammad Fethullah. Tasawuf Untuk Kita Semua (Menapaki Bukit-Bukit Zamrud Kalbu Melalui Istilah-Istilah dalam Prespektif Sufisme). Jakarta: Republika, 2014.

Hamka. Tasawuf Perkembangan dan Pemurniannya. Jakarta: Republika, 2016.

Haq, Muhammad Zaairul. Tasawuf Semar Hingga Bagong, Simbol, Makna, dan Ajaran Makrifat dalam Panakawan. Yogyakarta: Kreasi Wacana, 2009.

Hasan, Ismail. “Tasawuf: Jalan Rumpil Menuju Tuhan.” An-Nuha, Vol. 1, No. 1 (2014): 20.

Hasbi, Artani. "Hakikat Kebenaran Mengkaji Tasawuf Akhlaki - Akhlak Kenabian." MISYKAT: Jurnal Ilmu-ilmu Al-Quran, Hadist, Syari'ah dan Tarbiyah, Vol. 1, No. 2 (2016): 43, https://doi.org/10.33511/misykat.v1n2.43.

Hasbullah. Dasar-Dasar Ilmu Pendidikan. Jakarta: PT. Raja Grafindo, 2011.

Hasrinuksmo, Bambang. et. al., Ensiklopedi Wayang Indonesia. Jakarta: Sekretariat Nasional Pewayangan Indonesia, 1999.

Herawati, Nanik; D B Putut Setiadi; and Erry Pranawa. "Figure Of Semar In The Javanese Puppet Story as a Symbol of Character Building in the Javanese Society." in Literature, Tourism, and Multicultural Education in The Industrial Era 4.0, Vol. 1, 1. 29th International Conference On Literature And Hiski 36th Anniversary In Gorontalo 2020, Gorontalo: Gorontalo State University, 2021.

Husen, Achmad, et.al. "Pendidikan Karakter Berbasis Spiritualisme Islam (Tasawuf)." Jurnal Studi Al-Qur'an; Membangun Tradisi Berfikir Qur'ani, Vol. 10, No. 1 (2014): 1-19.

Isnaniah, Siti. "Dewa Ruci: Sebuah Alternatif Sistem Pendidikan." LiNGUA: Jurnal Ilmu Bahasa dan Sastra, Vol. 5, No. 1 (2011), https://doi.org/10.18860/ling.v5i1.612.

Izzati, Afina. "Nilai-nilai Konstruk Harmoni Perspektif Tokoh Wayang Semar." FIKRAH, Vol. 4, No. 2 (2017): 261, https://doi.org/10.21043/fikrah.v4i2.1631.

Kementerian Pendidikan dan Kebudayaan. “KBBI: Kamus Besar Bahasa Indonesia, n.d., https://kbbi.kemdikbud.go.id/entri/pendidikan. 
Lietz, Cynthia A. \& Luis E. Zayas. "Evaluating Qualitative Research for Social Work Practitioners," Advances in Social Work 11, no. 2 (September 28, 2010): 188202, https://doi.org/10.18060/589.

Ma`arif, Muhammad Anas. "Tasawuf Falsafi dan Implikasinya dalam Pendidikan Islam.” Jurnal Vicratina, Vol. 3, No. 1 (2018): 1-16.

Mahjudin. Kuliah Akhlak Tasawuf. Jakarta: Kalam Mulia, 1991.

Mayangsari, Marina Dwi. "Motivasi Berprestasi Mahasiswa Ditinjau dari Penerimaan Orangtua.” Jurnal Ecopsy, Vol. 1, No. 1 (2016): 21-27.

https://doi.org/10.20527/ecopsy.v1i1.480.

Mulyono, Sri. Wayang dan Filsafat Nusantara, Vol. 1. Jakarta: CV Haji Masagung, 1992, 1st ed..

Nasution, Harun. Filsafat dan Mistisisme dalam Islam. Jakarta: Bulan Bintang, 1973.

Nata, Abuddin. Ilmu Kalam, FIlsafat, dan Tasawuf "Dirasah Islamiyah IV." Jakarta: PT. Raja Grafindo, 2011

Notopertomo, Margono \& Warih Jatirahayu. 51 Karakter Tokoh Wayang Populer. Klaten: PT. Hafamira, 2012.

Nurcahyo, Jati. "Makna Simbolik Tokoh Wayang Semar dalam Kepemimpinan Jawa." Jurnal Media Wisata, Vol. 16, No. 2 (2018): 1069-1076 https://doi.org/10.36276/mws.v16i2.265.

Prasetiya, Benny; Bahar Agus Setiawan; dan Sofyan Rofi. "Implementasi Tasawuf dalam Pendidikan Agama Islam: Independensi, Dialog dan Integrasi." POTENSIA: Jurnal Kependidikan Islam, Vol. 5, No. 1 (2019): 64, https://doi.org/10.24014/potensia.v5i1.6553.

Purwadi. Mengkaji Luhur Tokoh Semar. Yogyakarta: Kanwa Publisher, 2014.

Rich, Wisma Nugraha Christianto. "Peran dan Fungsi Tokoh Semar-Bagong dalam Pergelaran Lakon Wayang Kulit Gaya Jawa Timuran." Humaniora, Vol. 15, No. 3 (2003): 286-301.

Rijali, Ahmad. "Analisis Data Kualitatif.” Alhadharah: Jurnal Ilmu Dakwah, Vol. 17, No. 33 (2019): 81, https://doi.org/10.18592/alhadharah.v17i33.2374.

Rorty, Richard; J.B. Cheneewind; and Quentin Skinner. Philosophy in History. Cambridge: Cambridge University Press, 1984.

Rozi, Syafwan. "Wacana Sufistik: Tasawuf Falsafi di Nusantara Abad XVII M: Analisis Historis dan Filosofis." Islam Realitas: Journal of Islamic \& Social Studies, Vol. 3, No. 2 (2017): 169, https://doi.org/10.30983/islam_realitas.v3i2.405;

Setiawan, Oke; I Made Kartika Dhiputra; and Ni Nyoman Sudiani. "Nilai-Nilai Filosofis dalam Karakter Tokoh Wayang Semar Perspektif Pendidikan Masyarakat Hindu Jawa di Pringsewu Lampung." Jurnal Pasupati, Vol. 5, No. 1 (2018): 104-124.

Setyaputri, Nora Yuniar. "Karakter Ideal Konselor Multibudaya Berdasarkan Nilai Luhur Semar.” Jurnal Kajian Bimbingan dan Konseling, Vol. 2, No. 2 (2017): 58-65, https://doi.org/10.17977/um001v2i22017p058. 
Siswanto, Nurhadi. "Filosofi Kepemimpinan Semar." Panggung, Vol. 29, No. 3 (2019), https://doi.org/10.26742/panggung.v29i3.1011.

Sri Mulyono, Wayang dan Filsafat Nusantara, Vol. 2, 2. Jakarta: CV Haji Masagung, 1992, 2nd ed.

Sugihartono, Ranang Agung "Antromorfisme dalam Kesenian Indonesia," Capture: Jurnal Seni Media Rekam, Vol. 2, No. 2 (2011): 31.

Suriadi. "Pendidikan Sufistik Tarekat Qadiriyyah wa Naqsyabandiyyah (Kajian atas Pemikiran Ahmad Khatib Sambas)." Khazanah: Jurnal Studi Islam dan Humaniora, Vol. $15, \quad$ No. 2 (2018): https://doi.org/10.18592/khazanah.v15i2.1899.

Suteja. Sufisme Lokal Mencari Akar Tradisi Tasawuf Indonesia. Cirebon: Pangger Publishing, 2016

Tim Penyusun Kamus Bahasa Indonesia. Kamus Bahas Indonesia. Jakarta: Pusat Bahasa, 2008.

Tjahyadi, Sindung. "Dekonstruksi Pemahaman Budaya Jawa tentang Hakikat dan Hubungan Kawula-Gusti pada Lakon Wayang Semar Kuning," Jurnal Filsafat, Vol. 19, No. 2 (2009): 23.

Undang-Undang Republik Indonesia Nomor 20 Tahun 2003 Tentang Sistem Pendidikan Nasional, 2003, https://www.unpad.ac.id/wp-content/uploads/2012/10/UU202003-Sisdiknas.pdf.

Yulistio, Didi \& Agus Joko Purwadi. "Study On Structure And Values Education In Stories Wayang Kulit." in Semirata, Vol. 1, 1 (International Seminar and Annual Meeting BKS-PTN Wilayah Barat, Palembang: Sriwijaya University, 2018), $136-45$.

Wahyudi, A. Bersatu Manunggaling Kawula Gusti. Jogjakarta: DIVA Press, 2014

Wibowo, Sekar Restika \& Tuti Hardjajani. "Kajian Nilai Bimbingan pada Tokoh Pewayangan Semar," CONSILIUM: Jurnal Program Studi Bimbingan dan Konseling, Vol. 3, No. 1 (2015): 7

Zohar, D. \& I. Marshal. Spiritual Intellegence: SQ The Ultimate Intelligence. London: Bloomsburry Publishing, 2001. 